Mirai. Estudios Japoneses

ISSN-e: 2531-145X

http://dx.doi.org/10.5209/mira.67180

\title{
Hacia una nueva era de los videojuegos japoneses. Superando el "valle inquietante" con Devil May Cry 5
}

\author{
Claudia Bonillo Fernández
}

Resumen. Desde sus inicios a mediados de los años setenta, la representación de la figura humana ha sido una constante en los videojuegos, habiéndose invertido mucho esfuerzo en desarrollar sistemas que permitan acercarlos lo más posible a las personas, un campo en el que la industria nipona ha sido pionera. Si bien la continua mejora de las tecnologías es deseable en una industria en constante evolución como es la de los videojuegos, ya que teóricamente permite ofrecer una mejor experiencia a los usuarios, esta tendencia hacia una representación fotorrealista de la figura humana ha dado lugar a un problema de escala global: muchos de los personajes de los videojuegos nos resultan inquietantes debido a que caen dentro del bukimi no tani genshō, conocido como 'fenómeno del valle inquietante' en español, término que alude al rechazo instintivo que suele provocarnos un ser artificial que imita la apariencia humana. En este artículo se pretende analizar el concepto del "valle inquietante" aplicado a los videojuegos nipones, analizando Devil May Cry 5 como estudio de caso que ha logrado superarlo, o está muy cerca de hacerlo, demostrando así que, gracias a su capacidad de trabajo e incesante renovación, Japón sigue estando a la vanguardia de la industria de los videojuegos.

Palabras clave: estudio de videojuegos; gráficos; valle inquietante; captura de movimiento; fotogrametría.

\section{[en] Into a New Era of Japanese Video Games. Overcoming the "Uncanny Valley" with Devil May Cry 5}

Abstract. Since its beginning in the mid-seventies, the representation of the human figure has been a constant in video games, and a great deal of effort has been invested in developing systems that bring virtual characters as close to people as possible, a field in which the Japanese industry has been pioneer. Although the continuous improvement of technologies is desirable in an industry in constant evolution such as the video games one, since it theoretically allows a better experience to users, this trend towards a photorealistic representation of the human figure has given rise to a problem on a global scale: many of the characters in video games are disturbing to us because they fall into the "bukimi no tani genshō", known as "uncanny valley phenomenon" in English, a term that alludes to the instinctive rejection provoked by an artificial being that imitates human appearance. This article aims to analyze the concept of the "uncanny valley" applied to Japanese video games, analyzing Devil May Cry 5 as a case study that has managed to overcome it, or is very close to doing so, thus demonstrating that, thanks to its work ethic and relentless improvement, Japan remains at the forefront of the video game industry.

Keywords: game studies graphics uncanny valley motion capture photogrammetry.

Sumario. 1. Introducción: descubriendo el valle inquietante; 2. Creando al humano perfecto. La industria de los videojuegos y la innovación tecnológica; 3. A la vanguardia de los videojuegos: Capcom y su saga Devil May Cry; 4 . Hiperrealismo vs. jugabilidad: las técnicas de Devil May Cry 5; 5. Conclusiones; 6. Bibliografía.

Cómo citar: Bonillo Fernández, C. Hacia una nueva era de los videojuegos japoneses. Superando el "valle inquietante" con Devil May Cry, en Mirai. Estudios Japoneses, 4, 2020, 87-98.

\section{Introducción: descubriendo el valle inquietante}

En 1970, Mori Masahiro (pref. Mie, 1927), fundador de la empresa Robocon y Presidente Emérito de la Robotics Society of Japan (日本ロボット学会), ${ }^{2}$ publicó en la revista Energy ${ }^{3}$ el artículo “Bukimi no tani”" en el que,

Universidad de Zaragoza; claudiabonfdez@gmail.com

Kawaguchi, J. (2011)

Título de una PR shi (PR誌) o "revista de relaciones públicas”, término que en Japón se aplica a revistas publicadas por empresas para dar a conocer sus avances y promocionarse teniendo, por tanto, poco aval científico. Energy, editada por la empresa petrolera Esso Standard Sekiyū (エッンスタ ンダード石油), actual JXTG Energy, desde abril de 1964 a diciembre de 1974 es una de las más conocidas. www.sogensha.co.jp (2008).

4 En los autores japoneses de cuyo nombre no se ha encontrado una transcripción oficial se incluyen los ideogramas del nombre entre paréntesis. Mori, M. (森政弘) (1970). En 2012 el artículo original recibió una traducción oficial al inglés, supervisada y aprobada por el propio profesor Mori. Mori, M. (2012). 
basándose en su experiencia trabajando con prótesis como profesor de robótica del Tokyo Institute of Technology ( 東京工業大学), explicaba cómo la relación entre la apariencia humanoide de los robots, o de los seres artificiales en general ${ }^{5}$, y la afinidad que las personas sentían por ellos no seguía una función monótona creciente, es decir, una mayor humanidad de la máquina no implicaba una mayor identificación con ella. Mori propuso que, aunque inicialmente la similitud de las máquinas con los seres humanos suscita una mayor empatía, llegado a un porcentaje cercano al cien por cien dicha avenencia cae en picado provocando por el contrario una sensación de extrañeza y malestar, denominando esta depresión en la gráfica con el término de "valle inquietante", siendo las razones que provocan este cambio de percepción poco claras ${ }^{6}$. Las observaciones de Mori, publicadas en una época en la que todavía no se fabricaban robots con apariencia humana ${ }^{7}$, no llamaron la atención hasta $2005^{8}$, año en que el concepto fue mencionado en una de las ponencias de la IEEE Robotics and Automation Society International Conference on Humanoid Robots 9 . Desde entonces, la teoría sugerida por Mori que, debido a la naturaleza divulgativa de la revista no llegó a demostrar científicamente y que, dada su naturaleza subjetiva ${ }^{10}$, ha contado con detractore ${ }^{11}$, ha sido explorada y corroborada desde muy distintos enfoques, incluido el de la neurociencia ${ }^{12}$, la psicología ${ }^{13} \mathrm{y}$, más recientemente, los videojuegos ${ }^{14}$. A pesar de la polémica que le rodea, el "valle inquietante" es un factor que se tiene en cuenta al valorar los gráficos de este medio de entretenimiento digita $1^{15}$ lo que, combinado con la solidez de los estudios que lo apoyan y la percepción personal que se tiene de este fenómeno, nos han llevado a utilizarlo como punto de partida para nuestro estudio. La novedad de la presente línea temática de investigación, sin embargo, dificulta la consulta de textos académicos convencionales, por lo que se ha recurrido a la consulta de fuentes online consideradas de prestigio dentro de la comunidad del desarrollo de videojuegos y de los game studies. De hecho, el análisis del valle inquietante resulta especialmente relevante en este ámbito ya que, según la teoría de Mori, la gráfica que lo modela se radicaliza cuando el humanoide artificial se mueve ${ }^{16}$. Los videojuegos, por tanto, con la constante interacción del jugador con el personaje virtual en continuo movimiento, se han enfrentado desde sus inicios a representar con naturalidad la figura humana cruzando este profundo valle, como veremos en el siguiente apartado.

\section{Creando al humano perfecto. La industria de los videojuegos y la innovación tecnológica}

Podemos localizar el origen de la industria ${ }^{17}$ de los videojuegos ${ }^{18}$ en el lanzamiento del simulador de tenis en dos dimensiones $P O N G$ (1972), desarrollado por la empresa americana Atari, en el que el jugador controlaba una línea vertical contra la que chocaba la pelota y que representaba al tenista. Desde el punto de vista de los gráficos, el primer avance hacia la representación de imágenes figurativas sería el sprite, que utilizaba la unidad más pequeña que podía manejar el ordenador, el píxel, para crear imágenes estilizadas de conceptos complejos ${ }^{19}$ y en los que la ejecución en serie representando distintos momentos de un mismo gesto daba apariencia de movimiento. Debido a las limitaciones gráficas, derivadas de la restringida memoria de las máquinas recreativas de la época, este tipo de

Entre los ejemplos que Mori menciona encontramos una muñeca de bunraku, una máscara de Noh, peluches y zombis. Ibidem.

El propio Mori sugería en su artículo que este malestar se debía al parecido que estos seres artificiales tenían con los muertos, atribuyendo el rechazo de las personas a un instinto primitivo de autoconservación. Ibidem. Posteriormente, han ido surgiendo otras teorías relacionadas con la traición de unas expectativas iniciales o el cuestionamiento de la propia identidad. Tinwell, A. / Grimshaw, M. / Williams, A. (2011): 328-329.

Se considera que el término "robótica" fue mencionado por primera vez en la historia Liar! de Isaac Asimov publicada en 1941, aunque los primeros robots no empezaron a fabricarse hasta los años cincuenta. www.computerhistory.org (2019). El primer robot humanoide, sin embargo, no se construiría hasta 1973, el WAseda roBOT-1, aunque a pesar de tener forma humana (dos brazos, dos piernas, torso, cabeza...) seguía manteniendo su apariencia mecánica. Hubo un salto cualitativo en el diseño de robots humanoides en los años noventa y principios de los dos mil, siendo Cybernetic Human HRP-4C en 2009 de los primeros robots que imitaba la apariencia y comportamiento humanos. Yoshida, E. (2019): 143-146.

El profesor Mori fue invitado a participar, pero debido a otros compromisos no pudo asistir. Kageki, N. (2012).

McDorman, K. F. (2005): 399.

Tinwell, A. / Grimshaw, M. / Williams, A. (2011): 328-329.

11 Uno de los principales opositores de esta teoría, el diseñador de robots David Hanson, defiende que algunos robots humanoides resultan atractivos para el público y que tienen el potencial para convertirse en la escultura del siglo XXI. Además, sostiene que pueden ser útiles para entender la inteligencia social. Hanson, D. / Olney, A. / Pereira, I. A. / Zielke, M. (2005): 30-31.

12 Braun, M. (2019).

13 Wang, S. / Lilienfeld, S. O. / Rochat, P. (2015).

14 Schneider, E. / Wang, Y. / Yang, S. / Potsdam, S. (2007).

D’Argenio, A. M. (2018).

16 Mori, M. (2012).

17 La invención del concepto de videojuego se atribuye al ingeniero americano de origen alemán Ralph H. Baer en 1951. Donovan, T. (2010). En los años sesenta empezarían a crearse los primeros videojuegos experimentales en ordenadores de los laboratorios de universidades y corporaciones, llegando al público general con la creación por Nolan Bushnell de las máquinas recreativas que funcionaban con monedas, lo que permitió rentabilizar el desarrollo de videojuegos. Wolf, M. J. P. (2008): 29.

18 Desde el comienzo de los game studies, ha existido controversia sobre la definición de los videojuegos, debido a su rápida evolución y al amplio rango de tecnologías que involucran. Idem: 3-7. El investigador Nicolas Espósito, por ejemplo, propone una definición general: "A videogame is a game which we play thanks to an audiovisual apparatus and which can be based on a story." Esposito, N. (2005): 2. En un intento de concretar la definición, unos años más tarde las profesoras de la University of Victoria (Canadá), Kathy Sanford y Leanna Madill definirían los videojuegos como "Games that use electronic systems (either personal computers or video game consoles) and involve interaction with a user interface to generate visual feedback on a video device". Ferdig, R. E. (2009): 355. Una definición más reciente, sin embargo, incluye el mercado móvil: "Video Games: Also called computer games or digital games, refers to a variety of interactive games played on different display platforms, for example gaming device, television, or mobile device". Li, J. (2019): 497.

19 Sherrod, A. (2008): 32. 
representaciones abstractas se mantendrían durante la década de los setenta en juegos tan diversos como el shooter ${ }^{20}$ Missile Radar (1973), en el que se manejaba un misil, el "juego de marcianitos" Space Invaders (1978), en el que se utilizaba el cañón de una nave espacial, o el fenómeno mundial de origen nipón Pac-Man (1980), en el que la falta de realismo del Comecocos protagonista no le impidió convertirse en uno de los personajes más famosos de la historia de los videojuegos ${ }^{21}$. En esta época es donde podemos situar las primeras representaciones de la figura humana en este medio, concretamente en videojuegos de Atari del género de deportes, como Basketball (1978), o shooters como Outlaw (1978), en los que se fueron sustituyendo las figuras geométricas que representaban al jugador por formas humanoides construidas mediante rectángulos ${ }^{22}$. Caricaturizado, pero más identificable que los ejemplos destacados hasta ahora sería Jumpman, protagonista del videojuego de la compañía nipona Nintendo Donkey Kong (1981), un fontanero italiano que posteriormente alcanzaría fama mundial bajo el nombre de Mario ${ }^{23}$. Junto con estos juegos también proliferaron aquellos pertenecientes al género de aventuras de texto ${ }^{24}$ que, ambientados con frecuencia en sociedades distópicas ${ }^{25}$, tenían como protagonista a las personas, como A Mind Forever Voyaging (1985), aunque sólo en unos pocos casos incluían su representación, y nunca de forma interactiva, por ejemplo las ilustraciones compuestas por píxeles del juego Fahrenheit 451 (1984), secuela de la novela de Ray Bradbury del mismo nombre ${ }^{26}$. Durante esa década y la siguiente, la difusión del CD-ROM, y con ellos los primeros avances en gráficos CGI

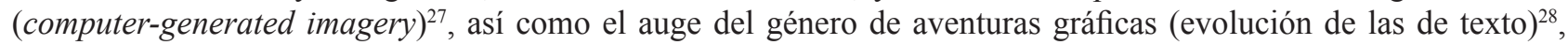
impulsarían la representación realista ${ }^{29}$ de la figura humana utilizando fotografías y dibujos digitalizados ${ }^{30}$, aunque estas técnicas obligaban a utilizar imágenes estáticas que entorpecían la jugabilidad ${ }^{31}$.

El siguiente hito en la representación de la figura humana en los videojuegos sería Prince of Persia $(1989)^{32}$, de la desarrolladora americana Brøderbund, considerado el primer juego que utilizaba uno de los sistemas predecesores de la captura de movimiento, la rotoscopia, técnica de animación en la que se calcan imágenes tomadas de filmaciones de actores reales para lograr una mayor naturalidad en los personajes animados, o virtuales en este caso ${ }^{33}$. Gracias a ella los movimientos del protagonista alcanzaron una fluidez desconocida hasta el momento.

La década de los noventa vería la aparición de los gráficos $3 \mathrm{D}^{34}$ con el videojuego americano de la Segunda Guerra Mundial Wolfenstein 3D (1992) que, a pesar de no ser el primer juego tridimensional, sí fue el responsable de popularizarlos ${ }^{35}$. Gracias a esta nueva tecnología los personajes dejaron de ser una secuencia de imágenes para tener su propio esqueleto, lo que permitía reproducir una gama de movimientos más amplia y con mayor naturalidad. Fue gracias a esta novedad que pudieron empezar a desarrollarse las primeras aplicaciones lúdicas de la captura de movimiento, llamada motion capture en inglés o simplemente mo-cap, que puede definirse como "[...] the process of recording a live motion event and translating it into usable mathematical terms by tracking a number of key points in space over time and combining them to obtain a single three-dimensional representation of the performance. ${ }^{\prime 36} \mathrm{El}$ origen de esta técnica se remonta a los años ochenta, durante los que se utilizaba principalmente para la investigación médica y militar ${ }^{37}$, siendo aplicada por primera vez a un videojuego en Virtua Fighter 2 (1994), de la compañía japonesa $\mathrm{Sega}^{38}$. La variante más utilizada ${ }^{39}$ en la actualidad es la optical motion capture, en la que se sitúan reflective markers ("marcadores brillantes") en el traje de captura de movimiento, especialmente en zonas móviles como las articulaciones, que permiten a las cámaras enviar la posición de dichos puntos al ordenador, trasladando así los movimientos de la persona al modelo $3 \mathrm{D}^{40}$ la misma técnica, aunque con marcadores más pequeños, puede utilizarse para registrar los gestos de la cara, así como guantes para los movimientos de las manos ${ }^{41}$.

La evolución natural de la captura de movimiento son los digital double, también conocidos como virtual actor, que no sólo integran los movimientos digitalizados de un actor en un modelo CGI creado por ordenador, sino que son una copia virtual (más o menos exacta) del mismo. Aunque en el cine se lleva experimentando con esta técnica

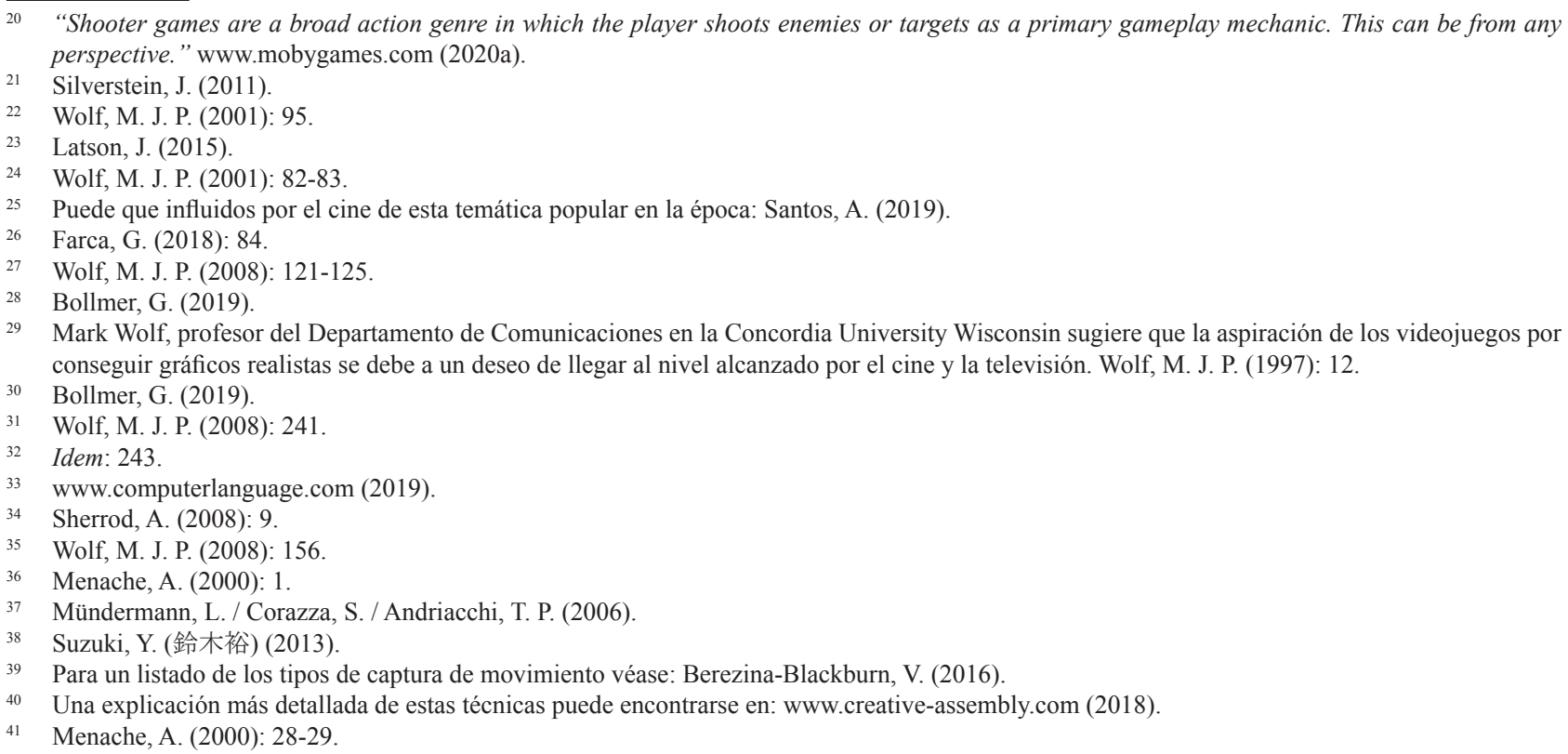


desde los años noventa ${ }^{42}$, no ha sido hasta la primera década del siglo XXI cuando la tecnología ha avanzando lo suficiente para combinar los dobles digitales con la interacción que caracteriza los videojuegos, siendo uno de los primeros ejemplos Beyond: Two Souls (2013), protagonizado por Willem Dafoe y Ellen Page ${ }^{43}$. Esta tendencia ha ido en aumento en los últimos años, siendo cada vez más los actores de Hollywood que prestan su rostro y dotes de actuación a la industria de los videojuegos ${ }^{44}$. Algunos de los ejemplos más célebres son la aparición de Keanu Reeves en Cyberpunk 2077 (2020), de la desarrolladora polaca CD Projekt Red, o el polémico Death Stranding (2019) del desarrollador japonés Kojima Hideo, en el que han participado los actores Norman Reedus y Mads Mikkelsen, entre muchos otros.

Podemos apreciar, por tanto, cómo la continua mejora de estas tecnologías, desde las cámaras del tamaño de pequeños frigoríficos en los años noventa, pasando por los programas comerciales que pueden adquirirse en la actualidad en el mercado ${ }^{45}$, llegando hasta al desarrollo de software que digitaliza los movimientos en tiempo real ${ }^{46}$, ha pavimentando la senda hacia los juegos hiperrealistas que disfrutamos hoy día.

\section{A la vanguardia de los videojuegos: Capcom y su saga Devil May Cry}

Una de las desarrolladoras que lleva en el mercado desde prácticamente la concepción de los videojuegos es Capcom, abreviatura del término capsule computer ${ }^{47}$, que celebró su cuarenta aniversario en 2019 . Fue creada en mayo de 1979 en la ciudad de Matsubara (pref. Osaka) ${ }^{48}$ bajo el nombre I.R.M. Corporation con el objetivo de desarrollar y

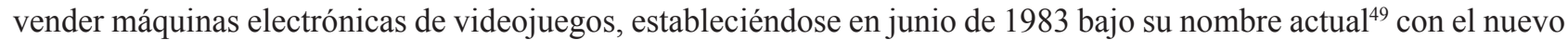
propósito de producir software, estrenando poco después su primera máquina recreativa operada con monedas, Little League (1983). Capcom no tardaría en expandir su área de influencia: dos años después fundarían CAPCOM U.S.A., con sede en California encargada de distribuir sus productos en Estados Unidos, seguida en 1989 por su sede en Reino Unido y en 1993 por CAPCOM ASIA en Hong Kong, convirtiéndose en una de las compañías de videojuegos niponas que más tempranamente alcanza proyección internacional. En los dos mil Capcom seguiría manteniéndose a la vanguardia de las nuevas tendencias introduciéndose con éxito en el mercado móvil estableciendo CAPCOM INTERACTIVE ${ }^{50}$, finalizando el año fiscal 2019 con algunos de los mejores resultados de los últimos tiempos ${ }^{51}$.

Capcom es también la autora de varios títulos que se han convertido en hitos de la historia de los videojuegos ${ }^{52}$. Ya uno de sus primeros lanzamientos, Ghosts 'n Goblins (1985), es considerado uno de los juegos más difíciles ${ }^{53}$. Unos años después, Street Fighter II (1991) marcaría un antes y un después en el género de peleas ${ }^{54}$ gracias a la incorporación de un gran número de personajes con fortalezas y debilidades bien definidas $\mathrm{y}$, sobre todo, a la introducción del sistema de combos. Seguidamente, Capcom redefiniría el género del survival horror ${ }^{55}$ con el lanzamiento de Resident Evil (1996), el primer juego 3D de la compañía que destacó, precisamente, por sus gráficos y el diseño de los enemigos ${ }^{56}$, lo que les permitió introducirse en el mercado cinematográfico mundial ${ }^{57}$. Otras franquicias famosas de la desarrolladora nipona incluyen Onimusha (2001), que ostenta el Premio Guinness al primer juego de PlayStation 2 que llegó a vender un millón de copias ${ }^{58}$, la serie RPG de éxito mundial Monster Hunter (2004) o la saga ambientada en el Japón feudal Sengoku Basara (2005), la cual ha contado con numerosas

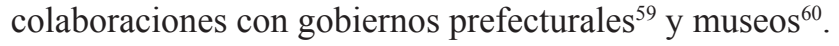

\footnotetext{
www.ukessays.com (2018).

Gallagher, J. (2015).

Shanley, P. (2019).

www.creative-assembly.com (2018).

Takahashi, D. (2016).

47 " [...] This was a phrase symbolic of an internal company objective to create a new gaming experience that would exceed that of rival personal computers [...]. The 'Capsule'segment of the CAPCOM name was based on 2 key concepts: 'a container packed to the brim with fun' and 'a desire to create securely packaged games to decrease the rapid expansion of pirated materials '.' www.capcom.co.jp (2019a).

48 En la actualidad, la sede principal sigue estando en Osaka, aunque ahora tienen varios edificios en la capital que les sirven de oficina. www.capcom. co.jp (2019b).

49 De septiembre de 1981 a junio de 1983 el nombre de la empresa principal era SANBI y el de la subsidiaria Japan Capsule Computer. Ibidem.

50 Esta empresa fue fundada en 2006. Posteriormente, en 2016, Capcom reorganizó la parte de su negocio dedicada al desarrollo de aplicaciones móviles creando Capcom Mobile. Ibidem.

$51 \quad$ www.capcom.co.jp (2019c).

52 Ronaghan, N. (2012).

53 Langshaw, M. (2015).

54 Houghton, D. (2008).

55 "Survival Horror games drop the player in a horror setting where survival against usually supernatural enemies is made difficult by sparse distribution of weaponry and ammunition and often a more realistic approach of the protagonists physical capabilities. The goal of these games is usually to escape the hazardous situation and trying to survive." www.mobygames.com (2020a).

56 McFerran, D. (2016).

$57 \quad$ www.capcom.co.jp (2015).

58 www.guinnessworldrecords.com (2019).

59 El personaje inspirado en el señor feudal Date Masamune ayudó a la revitalización de su prefectura de origen, Miyagi, durante las elecciones gubernamentales. www.capcom.co.jp (2009). El mismo personaje también ha formado parte de las campañas promocionales de la policía de Osaka. www.police.pref.osaka.lg.jp (2019).

60 www.saitama-rekimin.spec.ed.jp (2007).
} 
Dentro de estas franquicias icónicas ${ }^{61}$ desarrolladas por Capcom se incluye Devil May $\mathrm{Cry}^{62}$, pionera del género hack-and-slash ${ }^{63}$ con una fuerte presencia internacional ${ }^{64}$ que sigue las aventuras del caza-demonios Dante y su familia en un mundo contemporáneo alternativo. El padre de la serie es Kamiya Hideki, director de la saga Resident Evil, al que se le encargó dirigir una cuarta entrega de este survival horror más centrada en la acción ${ }^{65}$. Durante su desarrollo, sin embargo, las mecánicas de juego se distanciaron tanto de las de la serie principal que decidieron crear una IP aparte, dando lugar al lanzamiento de Devil May Cry (2001) para PlayStation 2, que supuso uno de los mayores éxitos de la compañía en críticas ${ }^{66}$ y en ventas ${ }^{67}$. Algunas de las novedades que se introdujeron fueron la carismática personalidad del protagonista, el combate aéreo ${ }^{68} \mathrm{y}$, especialmente, el sistema de estilo, según el cual el jugador obtiene puntos si derrota a los enemigos utilizando secuencias de combos no repetitivas y evitando daño "personal" ${ }^{69}$. En el extremo opuesto ${ }^{70}$ tenemos la segunda parte, Devil May Cry 2 (2003), en la que el cambio de director y un desarrollo plagado de problemas ${ }^{71}$ dieron lugar a una entrega oscura que introducía pocos cambios respecto a la anterior. La compañía se redimiría con Devil May Cry 3 (2005), considerado todavía por muchos como el mejor de la saga ${ }^{72}$, una precuela que recuperaba el tono desenfadado del juego original, e incluía una historia compleja con escenas cinemáticas de alta calidad a la vez que perfeccionaba el estilo de combate esbozado en los títulos anteriores ${ }^{73}$. La primera entrega para la nueva generación de consolas, Devil May Cry 4 (2008) introduciría a Nero, sobrino de Dante, como nuevo protagonista, cambiando con ello el tono establecido por sus predecesores y creando opiniones encontradas entre los aficionados ${ }^{74}$, aunque se aprecian mejoras en la jugabilidad que justifican sus excelentes ventas ${ }^{75}$. En un intento de recuperar la irreverencia que había caracterizado sus entregas más exitosas, Capcom encargó a la desarrolladora nipona Team Ninja hacer un reboot ${ }^{76}$, dando lugar a DmC: Devil May Cry (2013), un juego alejado de la saga principal tanto en estética como en jugabilidad que dividió a los fans ${ }^{77}$, a pesar de su moderado éxito en el mercado ${ }^{78}$. La franquicia volvería con toda su fuerza en PlayStation 4 con Devil May Cry 5 (2019), ganador en la categoría Best Action Game de los Game Awards 201979, una continuación de la saga familiar combinada con una vuelta a los orígenes en lo que respecta a las mecánicas de juego que no ha dejado indiferente a nadie $^{80}$.

\section{Hiperrealismo vs. jugabilidad: las técnicas de Devil May Cry 5}

Devil May Cry 5 ha supuesto la renovación de una saga clásica, así como el resurgir de Capcom tras años de estancamiento $^{81}$. El éxito a nivel mundial de esta nueva entrega se debe a la conjunción de muchos factores, entre los que podemos citar los nuevos y atractivos personajes, una historia que apela a los aficionados de siempre a la vez

${ }_{61} \quad$ Además de los videojuegos, la saga Devil May Cry incluye otros productos como cómics, manga, anime y crossover en distintos medios con otras series de la compañía, además de ediciones y colecciones especiales de los videojuegos de la serie principal. www.devilmaycry.fandom.com (2020).

62 Puede encontrarse más información sobre la historia de los distintos videojuegos que componen la franquicia en su web oficial: www.capcom.co.jp (2019e).

${ }^{63}$ "Games with hack and slash gameplay focus on combat with hand-to-hand weapons as opposed to guns, even though the presence of guns as additional weapons does not exclude the use of the genre. [...]”. www.mobygames.com (2020a).

${ }_{64}$ Junto con Resident Evil, Devil May Cry es de las sagas de Capcom con más presencia en el mercado Occidental. Tsujimoto, H. (2019): 33.

65 Yamagawa, J. (山川純) (2018).

66 Por dar una muestra, fue puntuado con un 9/10 en las revistas Game Spot y Eurogamer. Ahmed, S. (2001). Gestalt (2001).

${ }_{67}$ Todos los juegos de la serie Devil May Cry forman parte de la categoría Platinum Titles, nombre con el que Capcom se refiere a aquellos juegos que han superado el millón de ventas. La primera entrega vendió más de dos millones y medio de unidades. www.capcom.co.jp (2019d).

68 Esta nueva modalidad de combate surgió de un bug del juego precedente, Onimusha: mientras Kamiya probaba el videojuego, se dio cuenta de que los enemigos podían alzarle en el aire y golpearle. Se le ocurrió que sería una mecánica divertida para otro juego. Kurabe, E. (クラベ・エスラ) (2018).

69 Kamiya se inspiró en los salones de máquinas recreativas para su sistema de puntos de estilo, en los que los jugadores se motivaban para jugar mejor si había gente observándolos. Newnham, J. (2016).

70 Fue puntuado con un 6.4/10 en la revista Game Spot y con 5/10 en Eurogamer. Varanini, G. (2003). Reed, K. (2003). A pesar de las malas críticas, vendió 1.7 millones de unidades. www.capcom.co.jp (2019d).

71 Yamagawa, J. (山川純) (2018).

72 Stanton, R. (2013). Fue puntuado con un 8.6/10 en la revista Game Spot y con 8/10 en Eurogamer. Kasavin, G. (2005). Reed, K. (2005). Con las ventas de la edición original y la edición especial se convirtió en el juego con más ventas de la saga hasta el momento con 2.3 millones de unidades vendidas. www.capcom.co.jp (2019d).

73 Concretamente, añadía seis estilos distintos para manejar a Dante y la posibilidad de manejar a su hermano gemelo Vergil. Yamagawa, J. (山川純) (2018).

74 Matulef, J. (2011).

75 Fue puntuado con un 8/10 en la revista Game Spot y con 7/10 en Eurogamer. VanOrd, K. (2008). Reed, K. (2008). Superó las ventas de la entrega anterior con tres millones de unidades vendidas. www.capcom.co.jp (2019d).

76 Yin-Poole, W. (2010).

77 El nuevo diseño del protagonista causó un gran descontento entre los aficionados, aunque ejecutivos de Capcom aclararon que la reacción adversa de los fans formaba parte de su estrategia de marketing. Richardson, K. (2010).

78 Fue puntuado con un 9/10 en la revista Game Spot y con 8/10 en Eurogamer. Walton, M. (2015). Stanton, R. (2015). Vendió 2.4 millones de unidades. www.capcom.co.jp (2019d).

79 En el mismo festival fue además nominado en la categoría Best Score \& Music. thegameawards.com (2019).

80 Fue puntuado con un 9/10 en la revista Game Spot y forma parte de la lista Eurogamer Recommended de la revista del mismo nombre. Espineli, M. (2019). Robinson, M. (2019). Vendió 2.7 millones de unidades. www.capcom.co.jp (2019d).

81 Fillari, A. (2019). 
que permite introducirse en la franquicia a los nuevos fans, una endiablada jugabilidad ${ }^{82} \mathrm{y}$, no menos importante, un extraordinario apartado gráfico que ha llevado a algunos a plantearse si el valle inquietante no ha sido superado, o al menos, está muy cerca de serlo ${ }^{83}$. Este unánime elogio por el público y la crítica especializada lo erigen como un ejemplo sobresaliente dentro de esta generación de videojuegos, lo que merita un estudio más detallado de las tecnologías empleadas para la consecución de tan notables resultados.

Siguiendo el lema de “más moderno, mejor, más fuerte" (saishin, saikō, saikyō; 最新、最高、最強) ${ }^{84}$, la intención del equipo desarrollador liderado por el director Itsuno Hideaki ${ }^{85}$ era llevar hasta el límite el hardware de nueva generación para hacer un juego que pudiera confundirse con una película de Hollywood ${ }^{86}$. En este caso se enfrentaban, además, a un problema adicional derivado de la intensa jugabilidad que caracteriza la franquicia. Según palabras del productor Okabe Michiteru, la mejora de la tecnología puede llevar a la creación de seres virtuales que superen el valle inquietante, pero este objetivo se complica en extremo cuando es perentorio que dichos personajes se muevan con naturalidad, ya que puede darse lo que han acuñado como “el valle inquietante de la acción” (アクショ ンの不気味の谷, akushon no bukimi no tani), término que se refiere al fenómeno en el que personajes hiperrealistas se mueven de manera antinatural ${ }^{87}$.

Con estos objetivos en mente, como primer paso Yoshikawa Tatsuya, diseñador también de los personajes de Devil May Cry 4, preparó unos bocetos iniciales dibujados mediante técnicas tradicionales, actualizando el aspecto de los personajes habituales y definiendo las características de las nuevas adquisiciones ${ }^{88}$.

La primera novedad en el proceso de creación de los personajes fue buscar personas reales que fueran similares al arte conceptual de Yoshikawa con la intención de conseguir un aspecto fotorrealista, pero a la vez mantener la esencia de los personajes. Antes del perfeccionamiento de la captura de movimiento y, sobre todo, de los dobles digitales, los personajes se creaban desde cero con programas de ordenador, dando lugar a diseños fieles a los bocetos originales, pero poco realistas. El avance de la tecnología invirtió el proceso de diseño, en el que los desarrolladores de videojuegos se inspiraban en actores a la hora de modelar sus personajes ${ }^{89}$. Capcom, sin embargo, opta por seguir el proceso tradicional de adaptar la realidad a la ficción. Por supuesto, este nuevo enfoque no estuvo exento de problemas. Nadie en el territorio japonés cumplía sus expectativas, por lo que decidieron contactar agencias de modelos inglesas que les permitieron seleccionar gente de muy distintas procedencias que se ajustaba a su imagen de los personajes, dando lugar a un reparto internacional ${ }^{90}$.

Posteriormente, los modelos fueron escaneados en un estudio de fotogrametría, una técnica habitual en muchas ramas de la ciencia, especialmente en patrimonio ${ }^{91}$, que consiste en crear un modelo tridimensional de un objeto real tomando fotografías desde distintos ángulos que luego son combinadas mediante un programa de ordenador para reconstruir el objeto original ${ }^{92}$. Esta técnica, utilizada desde hace unos años en el ámbito de los videojuegos para la creación de ambientaciones realistas ${ }^{93}$, ya fue aplicada a personas por Capcom durante el desarrollo de Resident Evil 7 (2017); de hecho, la empresa nipona ya tenía instalado un estudio ${ }^{94}$ equipado con ciento tres cámaras digitales de la serie Canon EOS para fotografiar el cuerpo y treinta ocho para la cara que disparaban de manera sincronizada gracias al software Agisoft PhotoScan ${ }^{95}$. Sin embargo, seguramente para ahorrar los costes de desplazamiento y alojamiento de los modelos, en el caso de Devil May Cry 5 instalaron un estudio de fotogrametría en el extranjero ${ }^{96}$, gracias en gran medida a que, una vez situadas las cámaras, basta con saber su posición y ángulo para reproducir el mismo estudio en distintas partes del mundo.

En este punto merece la pena destacar el cuidadoso trabajo invertido en la fabricación de la indumentaria. Habitualmente, para replicar ropa fotorrealista en videojuegos es necesario tener vastos conocimientos de materiales, diseño y fabricación; luego, hay que pensar cómo le queda al personaje para poder replicarlo digitalmente, a la vez que se necesitan conocimientos de biología (movimiento del esqueleto, los músculos, la piel...) para poder

82 Todos estos aspectos se destacan en diversas críticas, citamos el ejemplo de Castellano, A. (2019).

83 Luna, L. (2019).

84 Devil May Cry Official YouTube Channel (2019).

85 En relación con la presente franquicia, también fue el director de Devil May Cry 4 y director supervisor de DmC. Además, ha sido director de diseño de los juegos de la saga desde Devil May Cry 2. www.mobygames.com (2020b).

86 Devil May Cry Official YouTube Channel (2019).

87 Shūka (秋夏) (2018).

88 Se han editado varios artbooks que compilan el arte conceptual de Devil May Cry 5. Por ejemplo, el que formaba parte de la edición coleccionista: Capcom (2019).

89 Paroni, N. (2018).

90 Según los créditos finales del videojuego, Adam Cowie (británico) es el modelo de Dante, Maxim Nazarov (ruso) es el modelo de su hermano Vergil, Karlo Baker (británico) de su sobrino Nero, Ariana Damant (medio griega medio inglesa) de su amiga Trish y Owen Mcginnity (medio irlandés medio libanés) es el modelo del nuevo personaje, $\mathrm{V}$, por nombrar algunos ejemplos.

91 Los Centros de Apoyo a la Investigación (CAI) e Instalación Científico Tecnológica Singular (ICTS) de la Universidad Complutense de Madrid, así como la startup de la Universidad de Zaragoza 3D Scanner ofrecen servicios de fotogrametría para la conservación del patrimonio. www.ucm. es (2019). 3dscanner.es (2017).

92 Para saber más, Guilherme Rambelli, artista 3D en la desarrolladora de videojuegos suiza EA DICE, colgó en su perfil de Art Station un completo tutorial sobre la técnica de fotogrametría aplicada al modelado de entornos realistas, explicando con detalle cada uno de los pasos. Rambelli, G. (2017).

93 Game Developers Conference (2016)

94 Egawa, Y. (2017): 38.

95 Ōno, K. (小野憲史) (2019).

96 Ibidem. 
ajustarla correctamente. En este caso, sin embargo, gracias a la potencia del hardware, en vez de crear las prendas manualmente por ordenador han podido escanearlas. Los atuendos, inspirados en las colecciones de Carol Christian Poell con su uso de metales y la mezcla de un estilo futurista con uno de otaku japonés, fueron diseñados de manera conjunta por el diseñador Yoshikawa y la modista londinense Madeleine Jenkins ${ }^{97}$ : el primero elegía los materiales basándose en la personalidad de los personajes (priorizando en ocasiones el diseño sobre la practicidad), y Jenkins aportaba su experiencia y los detalles (qué partes permitían más movilidad, la posición de las costuras, cuánto material se necesitaría, etc.), siendo además la encargada de coser las prendas desde cero, una tarea en la que invirtió medio año ${ }^{98}$. La ropa se acomodó posteriormente a los modelos seleccionados, que fueron escaneados caracterizados como sus respectivos personajes. La ropa fue enviada después desde Londres a Serbia, donde se escanearon los trajes en alta definición; dado que anteponían la respuesta inmediata a las acciones del jugador a la fidelidad a la prenda original, algunos detalles se minimizaron si reproducir el traje exigía demasiado computacionalmente ${ }^{99}$. Si bien todo este proceso resultó costoso, era más eficiente y producía mejores resultados que intentar modelar digitalmente ropa realista, pudiendo dedicar el resto del tiempo a mejorar la inmersión del jugador trabajando en los sombreados, envejecimiento de los personajes y progresivo ensuciamiento de la ropa.

En total, el modelo original de los personajes estaba compuesto de unos cien millones de polígonos. Tras el texturizado y las optimizaciones, al final quedaron unos modelos formados por ciento setenta mil polígonos de los cuales treinta y cinco mil correspondían a los trajes ${ }^{100}$.

Volviendo al diseño de personajes, uno de los puntos más sobresalientes es la animación facial, espontánea y llena de matices. Para lograrlo, el primer componente clave fue el nuevo motor gráfico ${ }^{101}$ que Capcom empezó a desarrollar en 2016, Reach for the Moon Engine (abreviado como RE Engine) ${ }^{102}$, diseñado específicamente para soportar los gráficos de Resident Evil 7 y programar juegos para las nuevas consolas de realidad virtual, que permite renderizar los nuevos gráficos en tiempo real; ${ }^{103}$ en palabras del programador líder de la sección de tecnología, Ishida Tomofumi, este motor surgió del convencimiento de que "Creating an interesting game should not be hindered by development engine constraints. If an artist expresses a desire to do something, the engine must evolve to make it happen." $104 \mathrm{El}$ segundo componente fue la empresa serbia 3Lateral, responsable de otros juegos con aclamada captura facial como Hellblade (2017) ${ }^{105}$. Desarrolladores de Capcom han concretado que, contrariamente a la técnica utilizada para crear dobles digitales donde se aspira a copiar de forma lo más fidedigna posible al original, en su caso decidieron hacer cambios y ajustes a los escáneres faciales y a los gestos de tal manera que se parecieran más a los personajes y menos a los modelos ${ }^{106}$.

El último punto a tener en cuenta son los movimientos, grabados en un nuevo estudio de mo-cap que construyeron recientemente y que cuenta con un techo de siete metros de alto, uno de los más grandes de Japón, permitiéndoles grabar un gran número de acrobacias desde diferentes alturas ${ }^{107}$. Debido a su nivel de detalle, convertir los escáneres $3 \mathrm{D}$ en esqueletos funcionales que permitieran una jugabilidad fluida resultó un proceso complejo. A esto se le añade otra técnica inusual utilizada por Capcom, que combina los talentos de diferentes profesionales para dar vida a un mismo personaje. Aunque es común utilizar dobles puntualmente para las escenas de riesgo y acrobacias, lo más frecuente es utilizar el rostro, movimientos y voz del mismo actor. Sin embargo, en palabras del productor Okabe: "For gestures unique to Japanese people, we need to get a Japanese actor to play the part. For voice, we need to use a Native English voice actor who can use proper pronunciation. "108 No sólo eso, sino que las animaciones faciales y los gestos del cuerpo se grabaron de forma separada y fueron acoplados posteriormente con minuciosidad, otra técnica poco manejada ${ }^{109}$. Por último, aunque no confirmado por Capcom, la difusión de imágenes de varios de sus actores de captura de movimiento llevando cascos de captura facial ${ }^{110}$ nos lleva a suponer que se ha utilizado una

\footnotetext{
97 Hodge, K. (2019).

98 Dado que la ropa estaba pensada para poder reproducirse en la realidad, parte del merchandising oficial de la serie son reproducciones de los abrigos de los personajes jugables cosidos por Jenkins y expuestos en el Tokyo Game Show 2018. Los materiales y medidas pueden encontrarse en el sitio oficial: www.e-capcom.com (2019).

99 Hodge, K. (2019).

100 Ōno, K. (小野憲史) (2019).

101 El motor de un juego (game engine en inglés), ya sea de ordenador o de consola, es el software que provee a los desarrolladores del conjunto de elementos necesarios para construir juegos de manera rápida y eficiente. Permite la importación de arte, de modelos 3D desde otro software y combinar estos elementos en escenas y ambientaciones concretas. Suelen permitir también añadir luz, sonido, efectos especiales, físicas y animación, interactividad y la lógica de la mecánica del juego, así como corregir los errores y optimizar el contenido para distintas plataformas. unity3d.com (2020).

102 Ishida, T. (2016): 5

103 Hidalgo, J. (2019).

104 Ishida, T. (2016): 5.

105 3lateral.com (2019).

106 Devil May Cry Official YouTube Channel (2018).

107 Egawa, Y. (2017): 38.

108 Okabe, M. (2018).

109 Devil May Cry Official YouTube Channel (2019).

110 En su canal oficial, Capcom colgó una entrevista con el actor de captura de movimiento de Dante desde Devil May Cry 3, Reuben Langdon, en el que se hacía una comparativa entre la primera escena cinemática donde aparece su personaje en Devil May Cry 5 y las correspondientes grabaciones en el estudio de captura de movimiento donde se le ve llevando este casco. Capcom Channel (2019). Unos días después, Brian Hanford, actor que da vida a V en el videojuego, colgó una foto de varios de sus compañeros en el estudio de captura de movimiento con cascos similares. Hanford, B. (2019).
} 
técnica más en la creación de expresiones hiperrealistas: combinando la textura ${ }^{111}$ obtenida mediante el escáner fotogramétrico de los rasgos de los modelos con las actuaciones de los actores de movimiento, han combinado expresiones realistas (surgidas de las dotes de actuación de los profesionales del cine) con el rostro atractivo de los profesionales de la moda. Los personajes se alejan, así, de las personas reales, manteniendo el fotorrealismo sin caer en el valle inquietante.

\section{Conclusiones}

Existe una predisposición en los últimos años a utilizar actores de carne y hueso en los videojuegos. Esto puede resultar beneficioso para la industria, ya que facilita publicitar el producto y permite ampliar el público objetivo, pero presenta a la vez importantes desventajas: limitarse a duplicar digitalmente a un actor aumenta las posibilidades de caer en el valle inquietante, resultando a día de hoy en extremo complejo reproducir con perfecta exactitud a una persona real, a la vez que desaprovecha las ilimitadas oportunidades que el medio digital nos ofrece para representar cualquier fantasía, pasando a convertirse en un mero reflejo de la realidad.

Devil May Cry 5, por su parte, gracias a la combinación de técnicas tradicionales (costura, fotogrametría...), con los últimos avances en captura de movimiento, es capaz de reproducir de manera hiperrealista personajes ficticios, representaciones ideales que bien podrían ser reales pero que son imposibles de encontrar. En suma, hace realidad nuestra imaginación. Utilizar este tipo de técnicas en los videojuegos ofrece considerables ventajas, ya que los desarrolladores no tienen que restringir sus diseños, a la vez que permite superar el valle inquietante ofreciendo personajes fotorrealistas sin equivalente en la realidad, favoreciendo que las expectativas de los espectadores no se vean traicionadas al comparar de manera inconsciente la versión real con la virtual.

Es especialmente significativo que este planteamiento haya venido de la mano de una empresa nipona veterana en el ámbito de los videojuegos como es Capcom, fundada en los inicios de la industria de este medio de entretenimiento, pero siempre reinventándose a lo largo de sus más de cuarenta años de existencia para estar a la vanguardia. Además, sus aportaciones a la industria no suelen ser el fruto de ilimitados medios económicos que les permiten desarrollar costosas y punteras nuevas tecnologías, sino que tienden a aplicar de forma novedosa conceptos ya existentes, dando lugar a una innovación fundamentada en lo corriente.

En conclusión, con este estudio de caso hemos demostrado que las desarrolladoras niponas todavía tienen mucho que ofrecer en el ámbito de los videojuegos ya que, si bien es innegable que el mercado estadounidense posee una superioridad económica que le permite estar en la cima de muchas industrias, incluida las de los videojuegos, la innovación no surge del dinero, sino de las ideas.

\section{Bibliografía}

3dscanner.es (2017): Photogrammetry, Ministerio de Industria, Comercio y Turismo. http://3dscanner.es/en/ photogrammetry/ [Consulta: 07/01/2020].

3lateral.com (2019): 3Lateral Studio is built around passion for creating characters and creatures, 3Lateral. https:// www.3lateral.com/index.html [Consulta: 07/01/2020].

Ahmed, Shahed (2001): “Devil May Cry Review”. En Game Spot, 17/10/2001. https://www.gamespot.com/reviews/devilmay-cry-review/1900-2818325/ [Consulta: 07/01/2020].

Berezina-Blackburn, Vita (2016): Motion Capture History, Technologies and Applications, The Ohio State University College of The Arts and Sciences. https://www.asc.ohio-state.edu/berezina-blackbu.1/classes/mocap/MotionCap tureOverview2016.pdf [Consulta: 07/01/2020].

Bollmer, Grant (2019): “The Kinesthetic Index: Video Games and the Body of Motion Capture". En: InVisible Culture: An Electronic Journal for Visual Culture, 30, Rochester. https://ivc.lib.rochester.edu/the-kinesthetic-index-videogames-and-the-body-of-motion-capture/ [Consulta: 07/01/2020].

Braun, Max (2019): “Scientists identify possible source of the Uncanny Valley in the brain”. En University of Cambridge - Research, 01/07/2019. https:/www.cam.ac.uk/ research/news/scientists-identify-possible-source-of-the-uncannyvalley-in-the-brain [Consulta: 07/01/2020].

Capcom (2019): The Art of Devil May Cry 5. China: Development Plus.

Capcom Channel (2019): Dante yaku no Ruuben tōjō! 'Debiru Mei Kurai 5’ Kapukon TV! \#99 (ダンテ役のルーベン 登場！『デビルメイクライ 5』カプコンTV! \#99; ;El intérprete de Dante, Reuben, entra en escena! ;Capcom TV Devil May Cry 5! \#99 [t.a.]) [vídeo digital], 13/03/2019. https://www.youtube.com/watch?v=TWFTb3TYxbw [Consulta: 07/01/2020].

Castellano, Álvaro (2019): “Análisis de Devil May Cry 5. El DMC que nos merecemos”. En 3D Juegos, 06/03/2019. https://www.3djuegos.com/juegos/analisis/32359/0/ devil-may-cry-5/ [Consulta: 07/01/2020].

111 Ōno, K. (小野憲史) (2019). 
Devil May Cry Official YouTube Channel (2018): Devil May Cry 5 - PAX West 2018 Panel [vídeo digital], 07/11/2018. https://www.youtube.com/watch?v=j7zJ08bZcHo [Consulta: 07/01/2020].

Devil May Cry Official YouTube Channel (2019): Devil May Cry 5 - Design Philosophy [vídeo digital], 15/03/2019. https://www.youtube.com/watch?v=comV8W-N5Z4 [Consulta: 07/01/2020].

devilmaycry.fandom.com (2020): List of Devil May Cry media, Devil May Cry Wiki. https://devilmaycry.fandom.com/ wiki/List_of_Devil_May_Cry_media [Consulta: 07/01/2020].

Donovan, Tristan (2010): “The Replay Interviews: Ralph Baer”. En Gamasutra, 29/11/2010. https://www.gamasutra. com/view/feature/134585/the_replay_interviews_ralph_baer.php [Consulta: 07/01/2020].

D’Argenio, Angelo M. (2018): “How Detroit: Become Human is ruined by the uncanny valley”. En Gamecrate, 08/06/2018. https://www.gamecrate.com/how-detroit-become- human-ruined-uncanny-valley/19568 [Consulta: 07/01/2020].

Egawa, Yōichi (2017): “Outfitting our Development Environment”. En Capcom Integrated Report 2017, 20/10/2017. http://www.capcom.co.jp/ir/english/data/pdf/ annual/2017/annual_2017_01.pdf [Consulta: 07/01/2020].

Espineli, Matt (2019): "Devil May Cry 5 Review - From Zero to Nero". En Game Spot, 11/03/2019. https://www. gamespot.com/reviews/devil-may-cry-5-review-from-zero-to- nero/1900-6417099/ [Consulta: 07/01/2020].

Esposito, Nicolas (2005): “A Short and Simple Definition of What a Videogame Is". En: DiGRA '05 - Proceedings of DiGRA 2005 Conference: Changing Views - Worlds in Play. Tokio: Digital Games Research Association. http://www. digra.org/digital-library/ publications/a-short-and-simple-definition-of-what-a-videogame-is/ [Consulta: 07/01/2020].

Farca, Gerald (2018): Playing Dystopia: Nightmarish Worlds in Video Games and the Player's Aesthetic Response. Wetzlar: Transcript.

Ferdig, Richard E. (2009): Handbook of Research on Effective Electronic Gaming in Education. Nueva York: Information Science Reference.

Fillari, Alessandro (2019): “Capcom Is Absolutely Killing It Right Now”. En Game Spot, 19/12/2019. https://www. gamespot.com/articles/capcom-is-absolutely-killing-it- right-now/1100-6466380/ [Consulta: 07/01/2020].

Gallagher, Jason (2015): “The Best - and Worst - of Celebrities in Video Games”. En Tribeca Film, 01/09/2015. https:// www.tribecafilm.com/stories/the-best-and-worst-of- celebrities-in-video-games [Consulta: 07/01/2020].

Game Developers Conference (2016): Star Wars: Battlefront and the Art of Photogrammetry [vídeo digital], 12/08/2016. https://www.youtube.com/ watch?v=U_WaqCBp9zo [Consulta: 07/01/2020].

Gestalt (2001): “Devil May Cry Review - Gestalt gets stuck into Shinji Mikami’s stylish new PlayStation 2 actioneer”. En Eurogamer, 08/12/2001. https://www.eurogamer.net/articles/r_dmc [Consulta: 07/01/2020].

Hanford, Brian (2019): Heroes are remembered, but legends do \#motioncapture! Part of the \#DMC5 crew doing what we do best! [tuit], 18/03/2019. https://witter.com/brihanford/status/1107756636003696640 [Consulta: 07/01/2020].

Hanson, David / Olney, Andrew / Pereira, Ismar A. / Zielke, Marge (2005): "Upending the Uncanny Valley". En: Proceedings, The Twentieth National Conference on Artificial Intelligence and the Seventeenth Innovative Applications of Artificial Intelligence Conference. Pittsburgh: AAAI, pp. 399-405. < doi: 10.1.1.505.5148>.

Hidalgo, Jason (2019): "Devil May Cry 5: Matt Walker talks Crew Cut, Turbo Mode, inertia and that cowboy dance". En Reno Gazette Journal, 22/03/2019. https:/eu.rgj.com/story/life/2019/03/09/dmc-5-s-matt-walker-talks-crew-cutturbo-mode-inertia-and-dante-dance/3105746002/ [Consulta: 07/01/2020].

Hodge, Kyle (2019): “How Capcom Crafted Signature Fashion Styles for Devil May Cry 5”. En Highs Nobiety, 28/08/2019. https://www.highsnobiety.com/ p/devil-may-cry-5-fashion-interview/ [Consulta: 07/01/2020].

Houghton, David (2008): "Why Street Fighter is still the most important fighting game series around". En Games Radar +, 14/02/2008. https:/www.gamesradar.com/ why-street-fighter-is-still-the-most-important-fighting-game-seriesaround/ [Consulta: 07/01/2020].

Ishida, Tomofumi (2016): "RE Engine: An Engine Enabling the Artist to Fulfill Their Every Wish". En Capcom Integrated Report 2016, 12/09/2016. http://www.capcom. co.jp/ir/english/data/pdf/annual/2016/annual_2016_01.pdf [Consulta: 07/01/2020].

Kageki, Norri (2012): “An Uncanny Mind: Masahiro Mori on the Uncanny Valley and Beyond”. En IEEE Spectrum, 12/06/2012. https://spectrum.ieee.org/automaton/robotics/ humanoids/an-uncanny-mind-masahiro-mori-on-theuncanny-valley [Consulta: 07/01/2020].

Kasavin, Greg (2005): “Devil May Cry 3: Dante’s Awakening Review”. En Game Spot, 28/02/2005. https://www. gamespot.com/reviews/devil-may-cry-3-dantes-awakening- review/1900-6119331/ [Consulta: 07/01/2020].

Kawaguchi, Judit (2011): "Robocon founder Dr. Masahiro Mori”. The Japan Times, 10/03/2011. https://www.japantimes. co.jp/life/2011/03/10/people/robocon-founder-dr- masahiro-mori/ [Consulta: 07/01/2020].

Kurabe, Esura (クラベ・エスラ)(2018): “Gensaku no hatsubai kara 17 nen, 'Onimusha'no miryoku to sono eikyō to ha?” (原作の発売から17年、『鬼武者』の鬼力とその影響とは?; Diecisite años desde la salida del juego original, ¿cuál es la influencia y el encanto de Onimusha? [t.a.]). En $I G N, 10 / 09 / 2018$. https://jp.ign.com/onimusha-2018/28807/ opinion/17 [Consulta: 07/01/2020].

Langshaw, Mark (2015): "The 12 hardest games ever made, from Ghosts ' $n$ Goblins to Dark Souls". En Digital Spy, 20/09/2015. https://www.digitalspy.com/video games/a669116/the-12-hardest-games-ever-made-from-ghosts-ngoblins-to-dark-souls/ [Consulta: 07/01/2020].

Latson, Jennifer (2015): "How Donkey Kong and Mario Changed the World". En Time, 02/06/2015. https://time. com/3901489/donkey-kong-anniversary/ [Consulta: 07/01/2020]. 
Li, Juan (2019): “A Systematic Review of Video Games for Second Language Acquisition”. En: Handbook of Research on Integrating Digital Technology with Literacy Pedagogies, Hershey, pp. 472-499. < doi: 0.4018/978-1-7998-0246-4. ch021>.

Luna, Laura (2019): “And kick some demon ass! Devil May Cry V, impresiones”. En Meristation, 07/02/2019. https:// as.com/meristation/2019/02/06/avances/1549490968_975753.html [Consulta: 07/01/2020].

Matulef, Jeffrey (2011): "Retrospective: Devil May Cry 4. The lost boys". En Eurogamer, 25/10/2011. https://www. eurogamer.net/articles/2011-05-22-retrospective- devil-may-cry-4-article [Consulta: 07/01/2020].

McDorman, Karl F. (2005): "Mortality salience and the uncanny valley". En: Proceedings of 2005 5th IEEE-RAS International Conference on Humanoid Robots. Piscataway: IEEE, pp. 399-405. < doi: 10.1109/ICHR.2005.1573600>.

McFerran, Damien (2016): "How Resident Evil redefined survival horror". En Digital Spy, 22/03/2016. https://www. digitalspy.com/videogames/resident-evil/a787741/how-resident-evil-redefined-survival-horror/ [Consulta: 07/01/2020].

Menache, Alberto (2000): Understanding Motion Capture for Computer Animation and Video Games. San Diego: Morgan Kauffman.

Mori, Masahiro (2012): “The Uncanny Valley: The Original Essay by Masahiro Mori”. En IEEE Spectrum, 12/06/2012. https://spectrum.ieee.org/automaton/robotics/ humanoids/the-uncanny-valley [Consulta: 07/01/2020].

Mori, Masahiro (森政弘) (1970): “Bukimi no tani” (不気味の谷; El valle inquietante [t.a.]). En Enajii - Robotto no gijutsu to shisō (エナジー・ロボットの技術と思想; Energía - Técnica e ideas de los robots [t.a.]), VII, 4, Tokio, pp. 33-35.

Mündermann, Lars / Corazza, Stefano / Andriacchi, Thomas P. (2006): "The evolution of methods for the capture of human movement leading to markerless motion capture for biomechanical applications" [versión digital]. En: Journal of Neuro Engineering and Rehabilitation, III. < doi:10.1186/1743-0003-3-6>.

Newnham, James (2019): “The Legacy of Devil May Cry”. En Keengamer, 06/02/2019. https:/www.keengamer.com/ article/20727_the-legacy-of-devil-may-cry [Consulta: 07/01/2020].

Okabe, Michiteru (2018): “Developer's Interview 2018. Ten Years in the Making: Pushing Stylish Action and Beautiful Graphics to the Limits in Devil May Cry 5". En Capcom - Investor Relations, 01/10/2018. http://www.capcom.co.jp/ ir/english/ interview/2018/vol03/ [Consulta: 07/01/2020].

Ōno, Kenshi (小野憲史) (2019): “Fotogurametorii de tsukuru 'Debiru Mei Kurai 5' no kyarakutaa moderu” (フォトグ ラメトリーでつくる『デビルメイクライ 5』のキャラクターモデル; Los modelos de personajes de Devil May Cry 5 hechos con fotogrametría [t.a.]). En CG World, 01/08/2019. https://cgworld.jp/feature/ 201908-gg2019-dmc5. html [Consulta: 07/01/2020].

Paroni, Nick (2018): "Video Game Characters Modeled After Famous Celebrities". En Vocal, 11/05/2018. https://vocal. media/gamers/video-game-characters-modeled-after-famous-celebrities [Consulta: 07/01/2020].

Rambelli, Guilherme (2017): “Photogrammetry Process Overview for Real-Time Use”. En Art Station, 02/05/2017. https://www.artstation.com/artwork/PZeJy [Consulta: 07/01/2020].

Reed, Kristan (2003): “Devil May Cry 2. Kristan bawls his way through Capcom's latest”. En Eurogamer, 01/05/2003. https://www.eurogamer.net/articles/r_dmc2_ps2 [Consulta: 07/01/2020].

Reed, Kristan (2005): “Devil May Cry 3. Limits pushed: difficulty, patience, skill, review policy, length of headline”. En Eurogamer, 08/05/2005. https://www.eurogamer.net/articles/r_devilmaycry3_ps2 [Consulta: 07/01/2020].

Reed, Kristan (2008): “Devil May Cry 4. I am cry”. En Eurogamer, 03/04/2008. https://www.eurogamer.net/articles/ devil-may-cry-4-review [Consulta: 07/01/2020].

Richardson, Kenneth (2010): “Capcom Says DMC Backlash Was Part of the Plan”. En Dual Shockers, 20/10/2010. https://www.dualshockers.com/capcom-says-dmc-backlash- was-part-of-the-plan/ [Consulta: 07/01/2020].

Robinson, Martin (2019): "Devil May Cry 5 review - an unashamedly old school return for an action legend". En Eurogamer, 12/03/2019. https:/www.eurogamer.net/articles/ 2019-03-06-devil-may-cry-5-review-an-unashamedlyold-school-retooling-of-an-action-classic [Consulta: 07/01/2020].

Ronaghan, Neal (2012): “A Visual History of Capcom's Success”. En IGN, 19/01/2012. https://www.ign.com/ articles/2011/08/25/a-visual-history-of-capcoms-success [Consulta: 07/01/2020].

Santos, Antonio (2019): Tiempos de ninguna edad. Distopía y cine. Madrid: Cátedra.

Schneider, Edward / Wang, Yifan / Yang, Shanshan / Potsdam, Suny (2007): "Exploring the Uncanny Valley with Japanese Video Game Characters”. En: DiGRA '07-Proceedings of the 2007 DiGRA International Conference: Situated Play. Tokio: Digital Games Research Association, pp. 546-549. < doi: 10.1.1.107.5258>.

Shanley, Patrick (2019): "Why More Stars Are Joining Video Games (It's Not Just a Paycheck)". En The Hollywood Reporter, 15/11/2019. https:/www.hollywood reporter.com/news/why-more-stars-are-joining-video-games-not-justa-paycheck-1254067 [Consulta: 07/01/2020].

Sherrod, Allen (2008): Game Graphics Programming. Boston: Course Technology.

Shūka (秋夏) (2018): “ ‘Debiru Mei Kurai 5’ Nero ha 'otōsan ni nitekiteiru’-Purodyūsaa intabyū! Sanninme no pureiaburu kyara no hinto ha igai na tokoro ni...? [E3 2018]”(『デビルメイクライ 5』ネロは「お父さんに似てきている」一 プロデューサーインタビュー！3人目のプレイアブルキャラのヒントは意外なところに ...?【E3２018】； Nero de Devil May Cry 5 'Se parece a su padre’ ¡Entrevista con el productor! ¿La pista sobre el tercer personaje jugable está en un lugar inesperado? [E3 2018] [t.a.]). En Game Park, 15/06/2018. https://www.gamespark.jp/article/ 2018/06/15/81653. html [Consulta: 07/01/2020]. 
Silverstein, Jonathan (2011): “Pac-Man: Ten Things You Didn't Know”. En ABC News, 08/03/2011. https://abcnews. go.com/Technology/GameOn/pac-man-10-secrets/story?id =13084900 [Consulta: 07/01/2020].

Stanton, Rich (2013): “Devil May Cry 3 retrospective. Dance with the devil”. En Eurogamer, 27/01/2013. https://www. eurogamer.net/articles/2013-01-27-devil-may- cry-3-retrospective [Consulta: 07/01/2020].

Stanton, Rich (2015): “DmC Devil May Cry review. Heaven and Hell.”. En Eurogamer, 11/03/2015. https://www. eurogamer.net/articles/2013-01-14-dmc-devil-may-cry-review [Consulta: 07/01/2020].

Suzuki, Yū (鈴木裕) (2013): “Dan bōru kara ningen ni sōzō mo dekinai shinka wo togeta” (段ボールから人間に想 像もできない進化を遂げた; Consiguió una evolución que nadie podía imaginar a partir de cajas de cartón [t.a.]). En Virtua Fighter 20 th Anniversary, 11/12/2013. http://vf20th.sega.jp/interview131211.html [Consulta: 07/01/2020].

Takahashi, Dean (2016): “Square Enix's mocap studio can capture and display an actor's movements in real time”. En Venture Beat, 04/12/2016. https://venturebeat.com/2016/12/04/square-enixs-mocap-studio-can-capture-and-displayan-actors-movements-in-real-time/ [Consulta: 07/01/2020].

thegameawards.com (2019): 2019 Nominees, The Game Awards. https://thegameawards.com/winners [Consulta: 07/01/2020].

Tinwell, Angela / Grimshaw, Mark / Williams, Andrew (2011): “The Uncanny Wall”. En: Int. J. Arts and Technology, Vol. IV, No. 3, Geneva, pp. 326-341. < doi: 10.1504/IJART.2011.041485 >.

Tsujimoto, Haruhiro (2019): "Enhance digital strategy and pursue maximizing revenue from IPs geared toward the expanding market”. En Capcom Integrated Report 2019, 15/10/2019. http://www.capcom.co.jp/ir/english/data/pdf/ annual/2019/annual_2019_01.pdf [Consulta: 07/01/2020].

unity3d.com (2020): Game engines-how do they work? Unity Technologies. https://unity3d.com/what-is-a-game-engine [Consulta: 07/01/2020].

VanOrd, Kevin (2008): “Devil May Cry 4 Review”. Game Spot, 05/02/2008. https://www.gamespot.com/reviews/devilmay-cry-4-review/1900-6185609/ [Consulta: 07/01/2020].

Varanini, Giancarlo (2003): "In the end, Devil May Cry 2 is a big disappointment, and it just isn't all that entertaining". Game Spot, 30/01/2003. https:/www.gamespot.com/reviews/devil-may-cry-2/1900-2909902/ [Consulta: 07/01/2020].

Walton, Mark (2015): “DmC: Devil May Cry Definitive Edition Review”. En Game Spot, 10/03/2015. https://www. gamespot.com/reviews/dmc-devil-may-cry-definitive- edition-review/1900-6416051/ [Consulta: 07/01/2020].

Wang, Shensheng / Lilienfeld, Scott O. / Rochat, Philippe (2015): "The Uncanny Valley: Existence and Explanations". En: Review of General Psychology, XXIX, 4, Washington D.C., pp. 393-407. < doi: 10.1037/gpr0000056>.

Wolf, Mark J. P. (1997): "Inventing Space: Toward a Taxonomy of On- and Off-Screen Space in Video Games”. En: Film Quaterly, LXI, 1, California, pp. 11-23. < doi: 10.1525/fq.1997.51.1.04a00030>.

Wolf, Mark J. P. (2001): The Medium of the Video Game. Austin: University of Texas Press.

Wolf, Mark J. P. (2008): The video game explosion: a history from Pong to Playstation and beyond. Londres: Greenwood Press. www.capcom.co.jp (2009): Sengoku BASARA Game Characters to be used in the Miyagi Prefecture Gubernatorial Election, Capcom. http://www.capcom.co.jp/ir/english/news/html/e091007.html [Consulta: 07/01/2020].

www.capcom.co.jp (2015): Special Feature: The Secret of Success “Resident Evil”, Capcom. http://www.capcom.co.jp/ ir/english/feature/ hit2013/02.html [Consulta: 07/01/2020].

www.capcom.co.jp (2019a): Origin of "Capcom” Name, Capcom. http://www.capcom.co.jp/ir/english/company/ philosophy.html [Consulta: 07/01/2020].

www.capcom.co.jp (2019b): History, Capcom. http://www.capcom.co. jp/ir/english/company/history.html?tab=3 [Consulta: 07/01/2020].

www.capcom.co.jp (2019c): Driven by digital shift in Consumer business, all profit items achieve highest levels in Capcom history despite dip in sales, Capcom. http://hunternet.capcom.jp/ir/english/news/html/e191029b.html [Consulta: 07/01/2020].

www.capcom.co.jp (2019d): Platinum Titles, Capcom. http://www.capcom.co.jp/ir/english/finance/million.html [Consulta: 07/01/2020].

www.computerhistory.org (2019): Timeline of Computer History: AI \& Robotics, CHM. https://www.computerhistory. org/timeline/ai-robotics/ [Consulta: 07/01/2020].

www.capcom.co.jp (2019e): Devil May Cry Series, Capcom. http://www.capcom.co.jp/devilmaycry/ [Consulta: 07/01/2020].

www.computerlanguage.com (2019): Computer Language, The Computer Language Company. https://www. computerlanguage.com/results.php? definition=rotoscoping [Consulta: 07/01/2020].

www.creative-assembly.com (2018): “Creative Chronicles: Motion Capture”. En Creative Assembly, 24/08/2018. https:// www.creative-assembly.com/blog/creative- chronicles- motion-capture [Consulta: 07/01/2020].

www.e-capcom.com (2019): Devil May Cry 5 Ultra Limited Edition, Capcom. https://www.e-capcom.com/sp/devil5/ [Consulta: 07/01/2020].

www.guinnessworldrecords.com (2019): First PlayStation 2 videogame to sell one million units, Guinness World Records. https://www.guinnessworld records.com/world-records/first-playstation-2-game-to-sell-over-1-millionunits/ [Consulta: 07/01/2020].

www.mobygames.com (2020a): Genre definitions, MobyGames. https://www.mobygames.com/glossary/genres [Consulta: 07/01/2020]. 
www.mobygames.com (2020b): Hideaki Itsuno, MobyGames. https://www.mobygames.com/developer/sheet/view/ developerId,61443/ [Consulta: 07/01/2020].

www.police.pref.osaka.lg.jp (2019): Kabushikigaisha Kapukon to Ōsaka-fu keisatsu ga renkei shita kōhōkatsudō 株式会社カプコンと大阪府警察が連携した広報活動; Actividades publicitarias llevadas a cabo en colaboración entre la policía prefectura de Osaka y la compañía pública Capcom [t.a.]), Osaka Prefectural Police. https://www. police.pref.osaka.lg.jp/seikatsu/anzen/1/2/6553.html [Consulta: 07/01/2020].

www.saitama-rekimin.spec.ed.jp (2007): Tokubetsuten “Sengoku Zukan - Cool Basara Style -” (特別展「戦国図鑑一 Cool Basara Style-; Exposición especial "Enciclopedia ilustrada de los Estados Combatientes - Cool Basara Style -”[t.a.]), Capcom. http://www.saitama-rekimin.spec.ed.jp/?page_id=417 [Consulta: 07/01/2020].

www.sogensha.co.jp (2008): PR shi no ōgon jidai wo furikaeru (PR誌の黄金時代を振り返る; Recordando la Edad de Oro de las revistas de relaciones públicas [t.a.]), Sōgensha. https:/www.sogensha.co.jp/page03/a_rensai/kosho/ kosho43e.html [Consulta: 07/01/2020].

www.ucm.es (2019): Arqueometría y Análisis Arqueológico, Universidad Complutense de Madrid. https://www.ucm.es/ cais?cai $=16 \& d e t=p c \& s=1$ [Consulta: 07/01/2020].

www.ukessays.com (2018): Virtual Acting In The Cinema Industry Film Studies Essay, All Answers. https://www. ukessays.com/essays/film-studies/virtual- acting-in-the-cinema-industry-film-studies-essay.php\#citethis [Consulta: 07/01/2020].

Yamagawa, Jun (山川純) (2018): Monhan korabo ni korekushon hatsubai! Ima dakara koso kataru 'Debiru Mei Kurai' shiriizu no kako to mirai (モンハンコラボにコレクション発売! 今だからこそ語る「デビルメイ クライ」 シリーズの過去と未来; ¡Sale a la venta la colección en colaboración con Monster Hunter! Ahora es el momento de hablar del pasado y del futuro de la serie Devil May Cry [t.a.]). En IGN, 25/03/2018. https://jp.ign.com/devil-may-cryhd-collection/23274/feature/ [Consulta: 07/01/2020].

Yin-Poole, Wesley (2010): “Ninja Theory's Devil May Cry confirmed”. En Eurogamer, 15/09/2010. https://www. eurogamer.net/articles/2010-09-15-ninja-theorys-devil-may- cry-confirmed [Consulta: 07/01/2020].

Yoshida, Eiichi (2019): "Robots that look like humans: a brief look into humanoid robotics". En: Mètode Science Studies Journal, 9, Valencia, pp. 143-151.<doi: 10.7203/metode.9.11405>. 